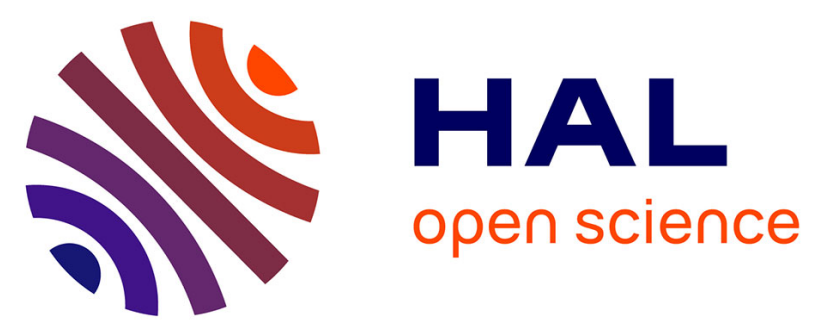

\title{
Changes in total leaf nitrogen and partitioning of leaf nitrogen drive photosynthetic acclimation to light in fully developed walnut leaves
}

Ela Frak, Xavier Le Roux, Peter P. Millard, Erwin E. Dreyer, Gaëlle G. Jaouen, B. B. Saint-Joanis, R. R. Wendler

\section{To cite this version:}

Ela Frak, Xavier Le Roux, Peter P. Millard, Erwin E. Dreyer, Gaëlle G. Jaouen, et al.. Changes in total leaf nitrogen and partitioning of leaf nitrogen drive photosynthetic acclimation to light in fully developed walnut leaves. Plant, Cell and Environment, 2001, 24 (12), pp.1279-1288. 10.1046/j.00168025.2001.00784.x . hal-00964585

\section{HAL Id: hal-00964585 \\ https://hal.science/hal-00964585}

Submitted on 1 Jun 2020

HAL is a multi-disciplinary open access archive for the deposit and dissemination of scientific research documents, whether they are published or not. The documents may come from teaching and research institutions in France or abroad, or from public or private research centers.
L'archive ouverte pluridisciplinaire HAL, est destinée au dépôt et à la diffusion de documents scientifiques de niveau recherche, publiés ou non, émanant des établissements d'enseignement et de recherche français ou étrangers, des laboratoires publics ou privés. 


\title{
Changes in total leaf nitrogen and partitioning of leaf nitrogen drive photosynthetic acclimation to light in fully developed walnut leaves
}

\author{
E. FRAK,${ }^{1,2}$ X. LE ROUX, ${ }^{1 *}$ P. MILLARD,${ }^{2}$ E. DREYER,${ }^{3}$ G. JAOUEN,${ }^{1}$ B. SAINT-JOANIS ${ }^{1}$ \& R. WENDLER ${ }^{2}$ \\ ${ }^{1}$ UMR-PIAF Integrated Tree Physiology (INRA-University Blaise Pascal), 234 avenue du Brézet, 63039 Clermont-Ferrand \\ cedex 02, France, ${ }^{2}$ Macaulay Land Use Research Institute, Craigiebuckler, Aberdeen AB15 8QH, UK and ${ }^{3} U M R$ INRA-UHP \\ Ecologie-Ecophysiologie Forestière, 54280 Champenoux, France
}

\begin{abstract}
Comprehensive studies on the processes involved in photosynthetic acclimation after a sudden change in light regime are scarce, particularly for trees. We tested (i) the ability of photosynthetic acclimation in the foliage of walnut trees growing outdoors after low-to-high and high-to-low light transfers made early or late in the vegetation cycle, and (ii) the relative importance of changes in total leaf nitrogen versus changes in the partitioning of leaf nitrogen between the different photosynthetic functions during a 2 month period after transfer. Changes in maximum carboxylation rate, light-saturated electron transport rate, respiration rate, total leaf nitrogen, ribulose 1.5-bisphosphate carboxylase/oxygenase (Rubisco) and total chlorophylls were surveyed before and after the change in light regime. Respiration rate acclimated fully within 1 week of transfer, and full acclimation was observed 1 month after transfer for the amount of Rubisco. In contrast, total nitrogen and photosynthetic capacity acclimated only partially during the 2 month period. Changes in photosynthetic capacity were driven by changes in both total leaf nitrogen and leaf nitrogen partitioning. The extent of acclimation also depended strongly on leaf age at the time of the change in light regime.
\end{abstract}

Key-words: Chlorophyll; electron transport capacity; maximum carboxylation rate; Rubisco.

\section{INTRODUCTION}

Leaf photosynthetic characteristics exhibit remarkable adaptability to light levels (Field \& Mooney 1986; Evans 1989). During expansion and growth, single leaves usually acclimate to the vertical gradient of mean irradiance encountered within plant stands (Hirose \& Werger 1987; Anten, Hernandez \& Medina 1996; Anten \& Werger 1996; Kull \& Niinemets 1998) or to the heterogeneous light

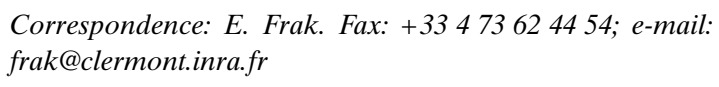

*Present address: Laboratoire d'Ecologie Microbienne des Sols (UMR 5557 CNRS-Université Lyon I), bat 741, 43 bd du 11 Novembre 1918, 69622 Villeurbanne, France. regime observed within individual tree crowns (DeJong \& Doyle 1985; Le Roux, Sinoquet \& Vandame 1999a; Le Roux et al. 2001). Generally, leaves developed at high irradiance exhibit higher nitrogen $(\mathrm{N})$ content and photosynthetic capacity per unit leaf area as compared with shade leaves (Boardman 1977; Givnish 1988; Sims \& Pearcy 1989; Niinemets, Kull \& Tenhunen 1998). Many studies have analysed the changes in leaf anatomical and biochemical characteristics that drive photosynthetic acclimation to light (Kappel \& Flore 1983; Seemann et al. 1987; Seemann 1989; Chazdon \& Kaufmann 1993; Hikosaka 1996; Rôças, Barros \& Scarano 1997; Niinemets et al. 1998). Because more than $50 \%$ of total leaf $\mathrm{N}$ is allocated to the photosynthetic apparatus (Evans \& Seemann 1989), photosynthetic acclimation to light has been described largely in terms of changes in total leaf $\mathrm{N}$ and/or in the partitioning of total leaf $\mathrm{N}$ between the different pools of the photosynthetic apparatus (Evans 1987; Chow et al. 1988; Hikosaka \& Terashima 1995).

In contrast, the processes involved in the photosynthetic acclimation of mature leaves following a sudden change in light regime (as observed after green pruning in tree orchards or gap formation in forests, for instance) is documented only poorly. Some studies have measured changes in the light-saturated photosynthetic rate and respiration rate of leaves after a change in light regime without analysing the concurrent changes in the main photosynthetic functions (i.e. light harvesting, electron transport and carboxylation) and in the key biochemical pools of the photosynthetic apparatus (von Caemmerer \& Farquhar 1984; Bauer \& Thoni 1988; Turnbull, Doley \& Yates 1993; Brooks, Hinckley \& Sprugel 1994; Naidu \& DeLucia 1997). In contrast, other studies have accurately quantified changes in a given photosynthetic function and/or a few biochemical characteristics of the leaves, such as the thylakoid compounds or Calvin cycle enzymes, generally under controlled conditions (Prioul, Brangeon \& Reyss 1980; Besford 1986; Davies et al. 1986; De la Torre \& Burkey 1990; Burkey \& Wells 1991; Evans 1993). To our knowledge, very few studies have surveyed the relative importance of concurrent changes in total leaf $\mathrm{N}$ versus changes in the partitioning of leaf $\mathrm{N}$ between light harvesting, electron transport and carboxylation after a sudden change in light regime. Evans (1989) studied changes in photosynthetic capacity, N con- 
tent and $\mathrm{N}$ partitioning in fully developed leaves of $\mathrm{Cucu}$ mis sativus subjected to changes in an irradiance regime. In Glycine max plants grown in a climate chamber, Pons \& Pearcy (1994) showed that after a high $\left(400 \mu \mathrm{mol} \mathrm{m}^{-2} \mathrm{~s}^{-1}\right)$ to low $\left(50 \mu \mathrm{mol} \mathrm{m}^{-2} \mathrm{~s}^{-1}\right)$ light transfer, photosynthetic acclimation resulted both from changes in total leaf $\mathrm{N}$ and from changes in the partitioning of leaf $\mathrm{N}$ within the photosynthetic apparatus. Such a comprehensive analysis of photosynthetic acclimation has never been made, either for plants growing outdoors or for trees.

The objectives of this study were to test (i) the ability of photosynthetic acclimation in hybrid walnut (Juglans nigra $\mathrm{x}$ regia) growing outdoors after low-to-high and highto-low light transfers made early or late in the vegetation cycle, and (ii) the relative importance of changes in total leaf $\mathrm{N}$ versus changes in the partitioning of $\mathrm{N}$ between the different photosynthetic functions during a 2 month period after transfer. We determined changes in maximum carboxylation rate, light-saturated electron transport rate, respiration rate, non-structural carbohydrates, total leaf $\mathrm{N}$, ribulose 1.5-bisphosphate carboxylase/oxygenase (Rubisco) and total chlorophyll before and after a change in light regime. The results are discussed in terms of the mechanisms involved in photosynthetic acclimation after a change in light regime.

\section{MATERIALS AND METHODS}

\section{Plant material and growth conditions}

One-year-old hybrid walnut trees (Juglans nigra $\mathrm{x}$ regia) were grown outdoors in $35 \mathrm{dm}^{3}$ pots filled with a soil/peat mixture $(1 / 2 \mathrm{v} / \mathrm{v})$. One lot of 161 -year-old plants was grown during 1999; another lot of 14 1-year-old plants was grown during 2000. To avoid complete light or shade exposure of the whole plant, each tree had only two opposite and erected branches. This was obtained by removing the apical and axillary buds before bud burst, with the exception of two vigorous axillary buds. Immediately after bud burst, the lower branch was placed in a tunnel made with altuglass screens. Two types of screen, mimicking high-light and deep-shade conditions, were used. The first (neutral) screen transmitted $90 \%$ of incident radiation without modification of the light spectrum ( $\mathrm{red} / \mathrm{far}$ red $=1.25)$, as measured with a spectroradiometer (LI-1800; Li-Cor Inc., Lincoln, NE, USA). The other (green) screen transmitted $10 \%$ of incident radiation $(\mathrm{red} / \mathrm{far} \mathrm{red}=0 \cdot 22)$. Plants were watered automatically once or twice a day according to evaporative demand.

The lower branches of eight and seven plants were grown in each screen tunnel during 1999 and 2000, respectively. Four plants were transferred from high- to low-light conditions and four were transferred from low- to highlight conditions on 29 July ( 91 d after bud burst) in 1999 and on 30 June ( $58 \mathrm{~d}$ after bud burst) in 2000. Four treatments were thus identified: constant low light (LL), constant high light (HH), low-to-high light transfer (LH) and high-to-low light transfer (HL). All physiological and biochemical mea- surements were subsequently made on single leaflets from fully developed leaves of the treated branch. The oldest and youngest leaves were excluded from these measurements. Air temperature and incident global radiation were recorded during the experiment period for both years.

\section{Leaf mass : area ratio and non-structural carbohydrates}

Leaflets were sampled on eight dates in 1999 and seven in 2000. One leaflet was harvested at random from each treated branch on each date. The leaflets' areas were measured with an area meter (LI-3100; Li-Cor), before they were freeze-dried and their dry mass measured. Samples were milled, and total non-structural carbohydrates (TNCs) [i.e. glucose fructose sucrose (GFS) and starch] were extracted prior to quantification. A hot ethanol : water buffer $(80: 20, \mathrm{v} / \mathrm{v})$ was used for GFS, then extracts were purified on ion-exchange resins (Bio-Rad AG 1-X8; Bio-Rad Lab., Hercules, CA, USA in the carbonate form and Dowex $50 \mathrm{~W}$ (Supelco, Belle Fonte, PA, USA) in the $\mathrm{H}^{+}$form. The amount of GFS was determined spectrophotometrically after a hexokinase, glucose-6-phosphate linked assay (Boehringer 1984). Starch was quantified by enzymatic assay after hydrolysis with amyloglucosidase (Boehringer 1984). The TNC-free leaf mass: area ratio (LMA) was computed as (total leaf dry mass - TNC mass) / fresh leaf area.

\section{Total leaf N, Rubisco and chlorophyll}

The amount of total leaf $\mathrm{N}$ per unit dry mass $\left(\mathrm{N}_{\mathrm{m}}, \%\right)$ was measured on the same dry samples with an elemental analyser (Carlo ERBA-1108; Carlo, Milan, Italy). Total leaf N was expressed per unit area $\left(\mathrm{N}_{\mathrm{a}}\right)$ as $\left(\mathrm{N}_{\mathrm{m}} \times\right.$ leaf dry mass $) /$ (fresh leaf area $\times 100$ ).

Total chlorophyll was estimated with a portable chlorophyll meter (SPAD-502; Minolta Camera Co., Osaka, Japan) on the leaflets used for leaf gas exchange measurements. SPAD data were converted into the total amount of chlorophyll per unit leaf area using a calibration curve $\left(y=0.0606 \mathrm{e}^{0.0502 \mathrm{x}}, N=64, r^{2}=0.87\right)$. This curve was established from destructive leaflet sampling, chlorophyll extraction in acetone and spectrophotometrical measurements according to Porra, Thompson \& Kriedemann (1989).

One $5 \mathrm{~cm}^{2}$ disc sampled on a fresh leaflet was used to quantify Rubisco on each date and for each branch. Discs were frozen immediately in liquid $\mathrm{N}_{2}$ and stored at $-80{ }^{\circ} \mathrm{C}$. Sampled discs were ground in liquid $\mathrm{N}_{2}$ until complete evaporation, then $5 \mathrm{~cm}^{3}$ of extraction buffer ( $\mathrm{pH} \mathrm{7.6)} \mathrm{con-}$ taining $100 \mathrm{~mol} \mathrm{~m}^{-3}$ Tris and $200 \mathrm{~mol} \mathrm{~m}^{-3}$ sodium borate was added. Three protease inhibitors $\left[10 \mathrm{~mm}^{3}\right.$ of each per $\mathrm{cm}^{3}$ of extraction buffer: $2.3 \mathrm{~mol} \mathrm{~m}^{-3}$ Benzamidine, $2 \mathrm{~mol} \mathrm{~m}^{-3} \in$ aminocarpic acid, $40 \mathrm{~mol} \mathrm{~m}^{-3}$ phenylmethylsulfonyl fluoride (PMSF)] and $500 \mathrm{mg}$ polyvinylpolypyrrolidone (PVPP) were also added. Rubisco extracts were centrifuged for $2 \mathrm{~min}$ at $14000 \mathrm{rpm}$ and diluted $1: 2000$. Elisa assays were performed as described by Catt \& Millard (1988) by the 
double antibody technique, using a $1: 1000$ dilution of primary polyclonal antibody raised in sheep against wheat Rubisco, and a 1:300 dilution of secondary antibody against sheep conjugated to alkaline phosphatase (Sigma A-5187). Purified Rubisco from wheat was used as a standard. The second antibody reacted with p-nitrophenol phosphate (Sigma 104-0) by developing yellow coloration. When sufficient colour had developed (5-10 $\mathrm{min}$ ), the reaction was stopped by the addition of $10 \mathrm{~mm}^{3} 5 \mathrm{~mol} \mathrm{~m}^{-3}$ $\mathrm{NaOH}$ and the optical density was read by a plate reader (Titertek Multiscan MCCl; Biolog Inc., Hayward, CA, USA).

\section{Gas exchange measurements}

Leaf gas exchange was measured with an infrared gas analyser-leaf chamber system (LI-6400, Li-Cor). Measurements were made on four dates in 1999 and seven in 2000. Leaf gas exchange was measured on the same leaflet of each plant throughout the experiment. Photosynthesis response curves to internal $\mathrm{CO}_{2}$ partial pressure $\left(A-p_{\mathrm{i}}\right)$ were established at a leaf temperature of $25^{\circ} \mathrm{C}$ and under high irradiance $\left(1200 \mu \mathrm{mol} \mathrm{m}{ }^{-2} \mathrm{~s}^{-1}\right)$ and different $\mathrm{CO}_{2}$ partial pressures $(190,150,110,90,70,50,35,25,20,15$ and $10 \mathrm{~Pa} \mathrm{CO}_{2}$ ). Respiration rate was measured after $20 \mathrm{~min}$ of acclimation in darkness at $25^{\circ} \mathrm{C}$ and $35 \mathrm{~Pa} \mathrm{CO}_{2}$. A version of the Farquhar \& von Caemmerer (1982) photosynthesis model proposed by Harley et al. (1992) was used to analyse the $A-p_{\mathrm{i}}$ curves. A fitting procedure (SAS software for Solaris version $6 \cdot 12$, SAS Institute Inc., Cary, NC, USA) was used to estimate the two key model parameters, i.e. maximum carboxylation rate $\left(V_{\text {cmax }}\right)$ and the light-saturated electron transport rate $\left(J_{\max }\right)$ (see Le Roux et al. 1999b).

\section{Calculations of leaf $\mathbf{N}$ partitioning between carboxylation, bioenergetics and light capture}

The model proposed by Niinemets \& Tenhunen (1997) was used to determine the coefficients for leaf $\mathrm{N}$ partitioning between carboxylation (mainly Rubisco) $\left(P_{r}\right)$, bioenergetics $\left(P_{\mathrm{b}}\right)$ and thylakoid light-harvesting components $\left(P_{1}\right)$ based on measured $\mathrm{N}_{\text {a }}$ values and estimated values of $V_{\text {cmax }}$, $J_{\max }$ and chlorophyll concentration. In this model, $P_{\mathrm{r}}$ is the foliar $\mathrm{N}$ investment in carboxylation capacity (i.e. influencing $\left.V_{\text {cmax }}\right), P_{\mathrm{b}}$ is the $\mathrm{N}$ investment for the capacity of electron transport (i.e. influencing $J_{\max }$ ) and $P_{1}$ is the $\mathrm{N}$ investment in light harvesting. $P_{\mathrm{r}}[\mathrm{g} \mathrm{N}$ in Rubisco (g total leaf $\left.\mathrm{N})^{-1}\right]$ and $P_{\mathrm{b}}[\mathrm{g} \mathrm{N}$ in cyt $f$, ferredoxin NADP reductase and coupling factor (g total leaf $\mathrm{N})^{-1}$ ] are given as follows:

$$
\begin{aligned}
& P_{\mathrm{r}}=V_{\mathrm{cmax}} /\left(6.25 \times V_{\mathrm{cr}} N_{\mathrm{a}}\right), \\
& P_{\mathrm{b}}=J_{\text {max }} /\left(8.06 \times J_{\mathrm{mc}} N_{\mathrm{a}}\right),
\end{aligned}
$$

where $V_{\text {cr }}$ is the specific activity of Rubisco [i.e. the maximum rate of RuBP carboxylation per unit Rubisco protein in $\mu \mathrm{mol} \mathrm{CO}_{2}$ (g Rubisco $\left.)^{-1} \mathrm{~s}^{-1}\right], J_{\mathrm{mc}}$ is the potential rate of photosynthetic electron transport per unit cyt $f$ [mol electrons (mol cyt $f)^{-1} \mathrm{~s}^{-1}$ ], $6 \cdot 25$ [g Rubisco (g N in Rubisco) $)^{-1}$ ] converts $\mathrm{N}$ content to protein content, and 8.06 [ $\mu \mathrm{mol}$ cyt $f$ ( $\mathrm{g} \mathrm{N}$ in bioenergetics) $)^{-1}$ is used assuming a constant $1: 1: 1 \cdot 2$ molar ratio for cyt $f:$ ferredoxine NADP reductase : coupling factor (Niinemets \& Tenhunen 1997). According to Niinemets \& Tenhunen (1997), at a leaf temperature of $25^{\circ} \mathrm{C}, V_{\mathrm{cr}}$ and $J_{\mathrm{mc}}$ are equal to $20 \cdot 2 \mu \mathrm{mol} \mathrm{CO}_{2}[(\mathrm{~g}$ Rubisco $\left.)^{-1} \mathrm{~s}^{-1}\right]$ and $156 \mathrm{~mol}$ electrons [(mol cyt $\left.\left.f\right)^{-1} \mathrm{~s}^{-1}\right]$, respectively. $P_{1}$ [g N in PSI, PSII and LCHII (g total leaf $\mathrm{N})^{-1}$ ] is computed in a similar way, assuming scaling relationships between (i) $J_{\max }$ and cyt $f$, and (ii) the different thylakoid chlorophyll-protein complexes and cyt $f$ (for details, see Eqn 6 and appendix B in Niinemets \& Tenhunen 1997; see also Hikosaka \& Terashima 1995). Nitrogen investment in carboxylation was also estimated directly from measured total $\mathrm{N}$ and Rubisco amounts and was compared with values calculated according to Niinemets \& Tenhunen (1997).

\section{Statistical analyses}

Statistical analyses were performed with the Genstat $4 \cdot 2$ software developed by Genstat Committee; IACRRothansted, Harpenden, UK. The residual maximum likelihood (REML) procedure was applied for the analysis of variance components on repeated measurements and unbalanced data sets. This procedure allowed overall tests of treatment $(T)$, date $(D)$ and treatment $\times$ date interaction (I). Because the various parameters were observed through time on the same individuals, ante-dependence analysis (Gabriel 1962) was used to assess the times at which treatment effects occurred.

\section{RESULTS}

\section{Comparison of leaf stage between the two years}

The seasonal courses of global incident radiation and air temperature were very similar for the two years (Fig. 1). The average global irradiances from June to mid-September were 19.24 $\pm 6 \cdot 31$ and 19.66 $\pm 6 \cdot 74 \mathrm{MJ} \mathrm{m}^{-2}$ during 1999 and 2000, respectively. The average air temperatures for the same period were $19 \cdot 1 \pm 2 \cdot 7$ and $18 \cdot 9 \pm 3.0{ }^{\circ} \mathrm{C}$ in 1999 and 2000 , respectively.

The time and duration of bud break (late April and early May) was also similar for the two years (Fig. 1). $\mathrm{N}_{\mathrm{m}}$ decreased from 2.8 to $1.5 \%$ from the end of June to September. At a given date, values were similar in 1999 and 2000 (Fig. 2). Leaf $\mathrm{N}_{\mathrm{m}}$ was greater when plants were transferred in late June $2000(2 \cdot 8 \%)$ than in late July 1999 $(2.0 \%)$. Therefore, leaves did not have a comparable age or $\mathrm{N}$ status when the treatments were imposed during the two years.

\section{LMA, starch and soluble sugars}

In 1999, the LMA and the amount of starch and soluble sugars per unit leaf area were higher for leaves developed under sun conditions than for those developed in the shade (Fig. 3). LMA and non-structural carbohydrate values of 

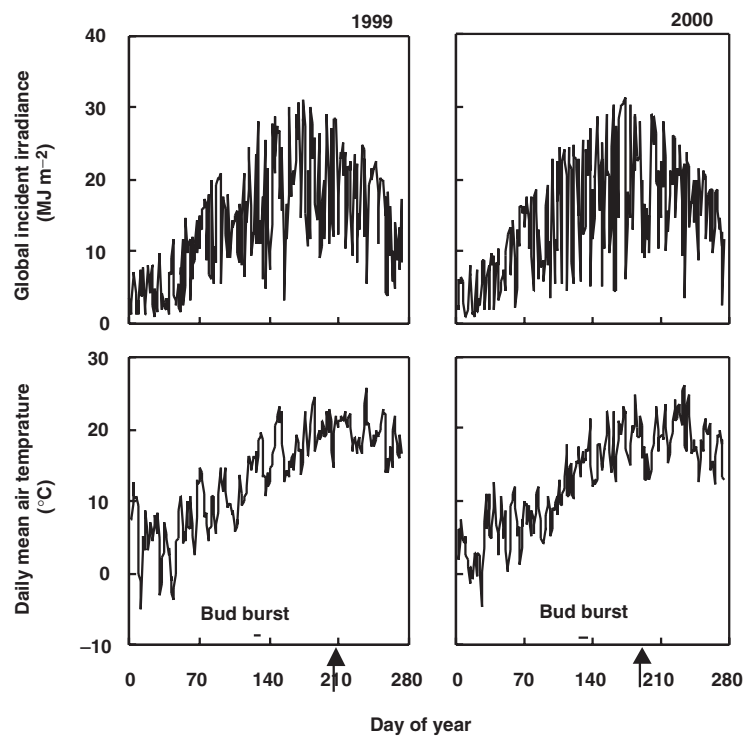

Figure 1. Seasonal courses of global incident radiation and daily mean air temperature from 1 January to 15 September in 1999 and 2000. Horizontal bars indicate the time and duration of bud burst. Arrows indicate the dates of transfers.

transferred leaves did not change after transfer. Starch exhibited a slight decrease with time in all treatments.

In 2000, LMA was constant or increased slightly in the $\mathrm{HH}, \mathrm{HL}$ and LL treatments during the 2 month measurement period (Fig. 3). In contrast, LMA increased from 35 to $55 \mathrm{~g} \mathrm{~m}^{-2}$ during the same period in the LH treatment. During the first month after transfer, the amount of starch remained roughly constant for the $\mathrm{HH}, \mathrm{HL}$ and LL treatments, whereas it increased from around 4 to $6 \mathrm{~g} \mathrm{~m}^{-2}$ in the LH treatment. The amount of starch per unit area decreased rapidly in all treatments after day 210. The

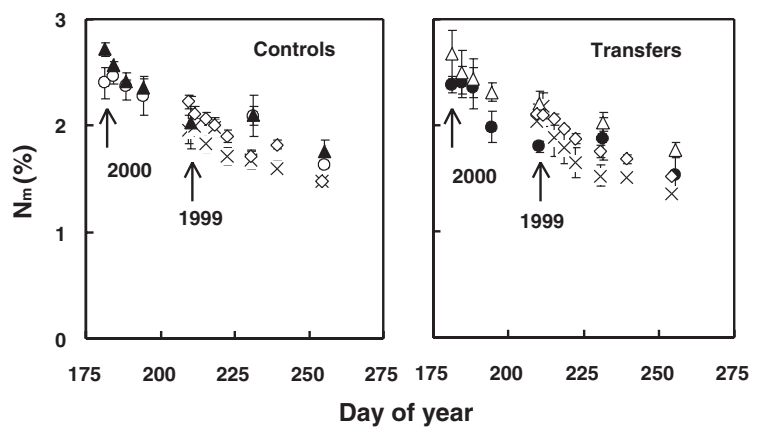

Figure 2. Temporal courses of nitrogen concentration $\left(\mathrm{N}_{\mathrm{m}}\right)$ for leaves of the HH treatment in $1999(\diamond)$ and $2000(\bigcirc)$; LL treatments in $1999(\times)$ and $2000(\mathbf{\Delta})$; HL treatments in $1999(\diamond)$ and $2000(\mathbf{)})$, and LH treatments in $1999(\times)$ and $2000(\triangle)$. Arrows indicate the dates of transfers. Bars indicate standard errors ( $n=4$ for all treatments in 1999; in 2000, $n=3$ for HH and LL and $n=4$ for HL and LH). Significant effect of treatments (T) was observed only in $1999(P=0 \cdot 014)$; dates $(D)$ always had a significant effect $(P<0 \cdot 001)$, but the interaction $(I)$ between treatments and dates was not significant (NS).
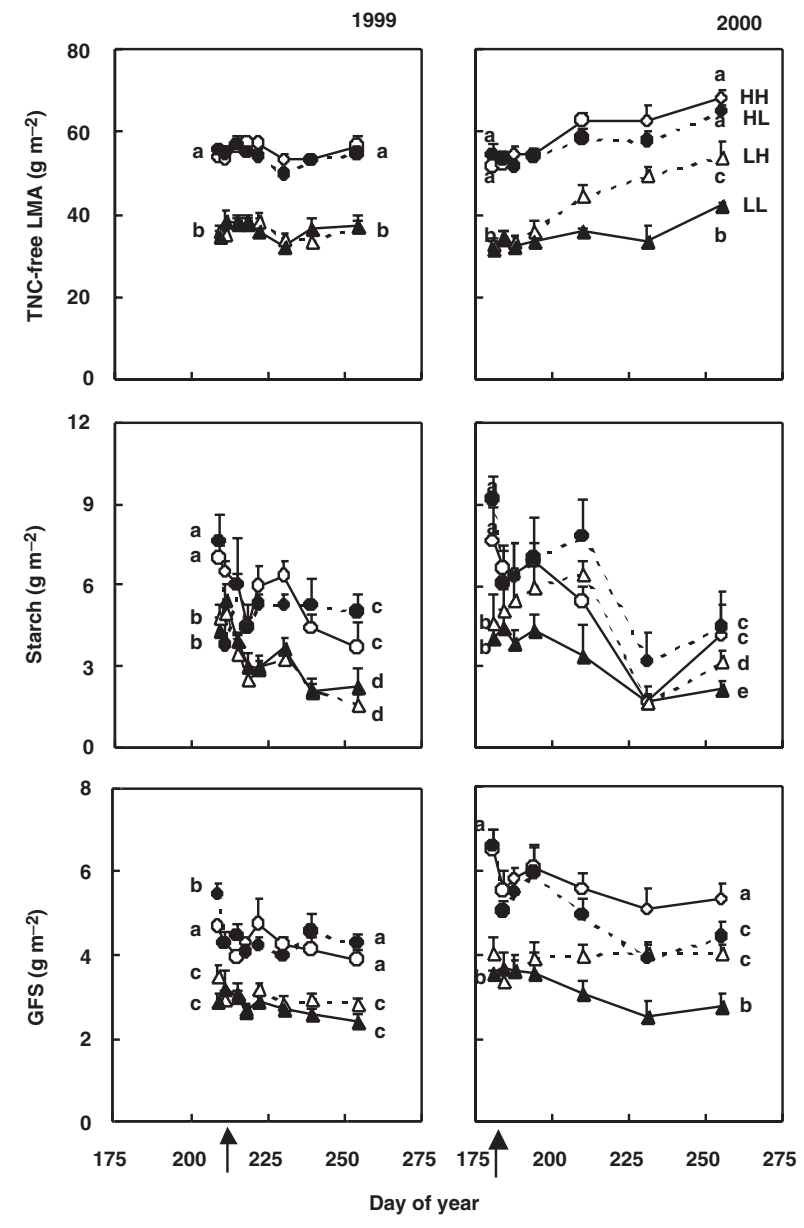

Figure 3. Temporal courses of the TNC-free leaf mass : area ratio (LMA), and the amount of starch and soluble sugars (GFS) per unit leaf area. Values are presented for high-to-high $(O)$ and low-to-low ( $\mathbf{\Delta})$ (both with solid lines), and high-to-low (O) and low-to-high $(\triangle)$ (both with dashed lines) treatments in 1999 and 2000. Arrows indicate the dates of transfers. Bars indicate standard errors $(n=4$ for all treatments in 1999; in 2000, $n=3$ for HH and LL and $n=4$ for HL and LH). In 1999 and 2000, significant $T$ $(P<0.001)$ and $D(P<0.001)$ effects were observed on LMA ( $I=$ NS in both years). $T, D(P<0 \cdot 001)$ and $I(P=0 \cdot 001)$ had significant effects on starch amount in 1999. In 2000, $T$ and $D$ had a strong effect $(P<0.001)$ on starch $(I=\mathrm{NS})$. In $1999, I$ was NS whereas $T$ and $D$ had significant effects $(P<0 \cdot 001)$ on GFS. In $2000, T, D$ and $I$ had strong effects on GFS $(\mathrm{P}<0 \cdot 001)$. Significant differences on a few dates are indicated by letters.

amount of soluble sugars per unit leaf area decreased slightly in the $\mathrm{HH}$ and LL treatments. In contrast, soluble sugar content increased with time for the LH treatment and decreased for the HL treatment as compared with the constant LL- and HH-grown plants.

\section{Total leaf $\mathbf{N}$, Rubisco and chlorophylls}

In 1999, $\mathrm{N}_{\mathrm{a}}$ was higher in sun than in shade leaves, and values decreased with time in all treatments (Fig. 4). $\mathrm{N}_{\mathrm{a}}$ of transferred leaves did not change as compared with constant light leaves. However, in $2000, \mathrm{~N}_{\mathrm{a}}$ increased by about 

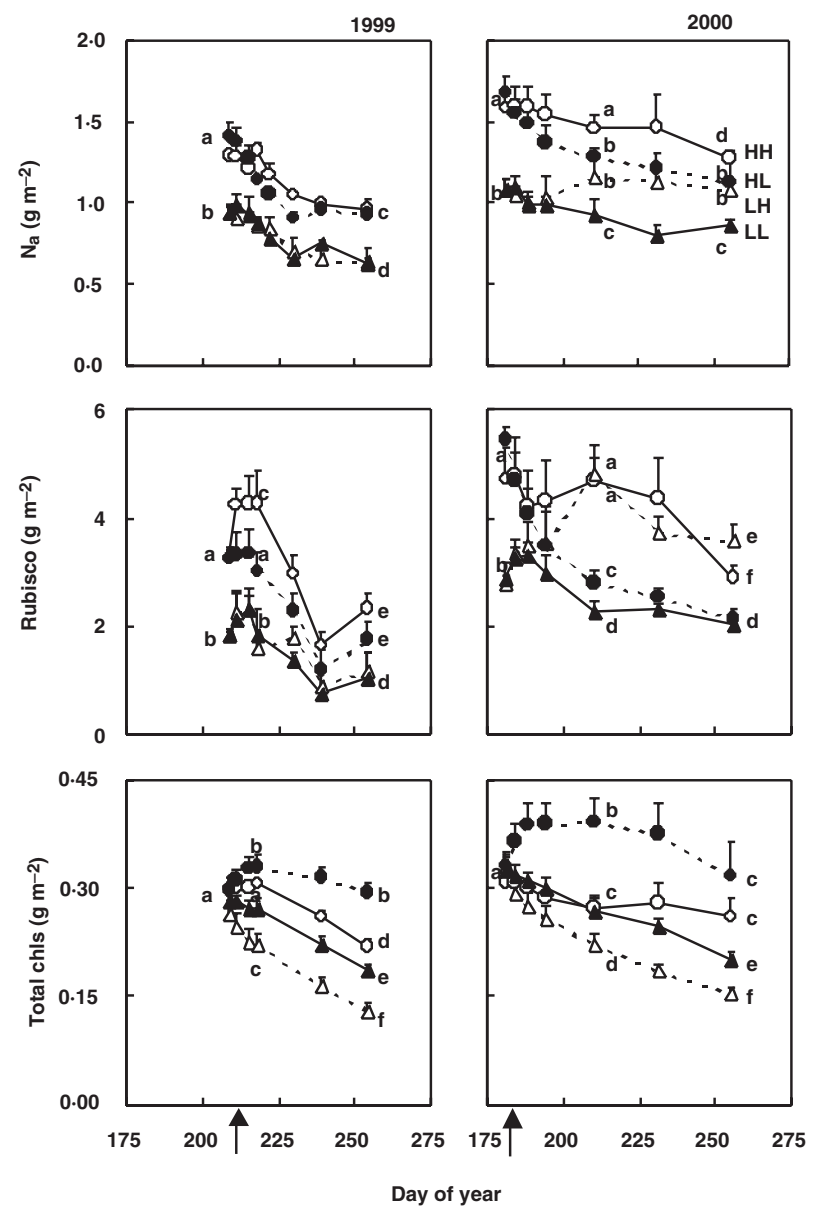

Figure 4. Temporal courses in the amount of total leaf nitrogen $\left(\mathrm{N}_{\mathrm{a}}\right)$, Rubisco and total chlorophylls (Total chls) per unit leaf area in 1999 and 2000. Symbols as in Fig. 3; bars indicate standard errors. In 1999 and 2000, $\mathrm{N}_{\mathrm{a}}$ was affected significantly by $T$ and $D$ $(P<0.001)$, but $I$ was NS. $T(P<0 \cdot 001)$ and $D(P=0.001)$ had significant effects on Rubisco in both years; $I$ was only significant in $2000(P<0.001)$. In both years, $T, D$ and $I$ had strong effects on total chls $(P=0 \cdot 001)$. Significant differences on a few dates are indicated by letters.

$40 \%$ in the $\mathrm{LH}$ treatment and decreased by $30 \%$ in the HL treatment as compared with the corresponding controls (LL and $\mathrm{HH}$, respectively).

The amount of Rubisco per unit leaf area decreased throughout the experiment for all treatments in 1999. Values in HL leaves became lower than those in $\mathrm{HH}$ leaves after transfer. In 2000, Rubisco increased for the LH treatment and decreased for the HL treatment. The amount of Rubisco was similar within $30 \mathrm{~d}$ of transfer in $\mathrm{LH}$ and $\mathrm{HH}$ treatments, and within $40 \mathrm{~d}$ in HL and LL treatments.

During both years, total chlorophyll levels changed within a few days of transfer. Before transfer, the amount of chlorophyll per unit area was similar between shade and sun leaves. However, after transfer, chlorophyll decreased significantly in LH treatments and increased in HL treatments.

\section{Photosynthetic capacities}

During both years, $V_{\text {cmax }}$ and $J_{\max }$ were higher in sun than in shade leaves. $V_{\text {cmax }}$ and $J_{\max }$ decreased with time in all treatments (Fig. 5). In 1999, the leaf photosynthetic capacities of transferred leaves remained close to the values of the corresponding controls after transfer. In contrast, the respiration rate of HL leaves decreased rapidly after transfer and was similar to that of LL leaves 1 week after transfer. The respiration rate of $\mathrm{LH}$ leaves did not differ from values for LL leaves during the study period.

In $2000, V_{\text {cmax }}$ decreased by around $40 \%$ in the HL treatment and increased by $25 \%$ in the LH treatment. Concurrently, $J_{\max }$ decreased by around $35 \%$ in HL and increased by $45 \%$ in $\mathrm{LH}$ treatment. Respiration rate acclimated fully within 2 weeks of transfer in both LH and HL treatments. Full acclimation was defined as occurring when plants transferred to the new light condition produced values for the various parameters that were the same as those for plants grown constantly under this condition.
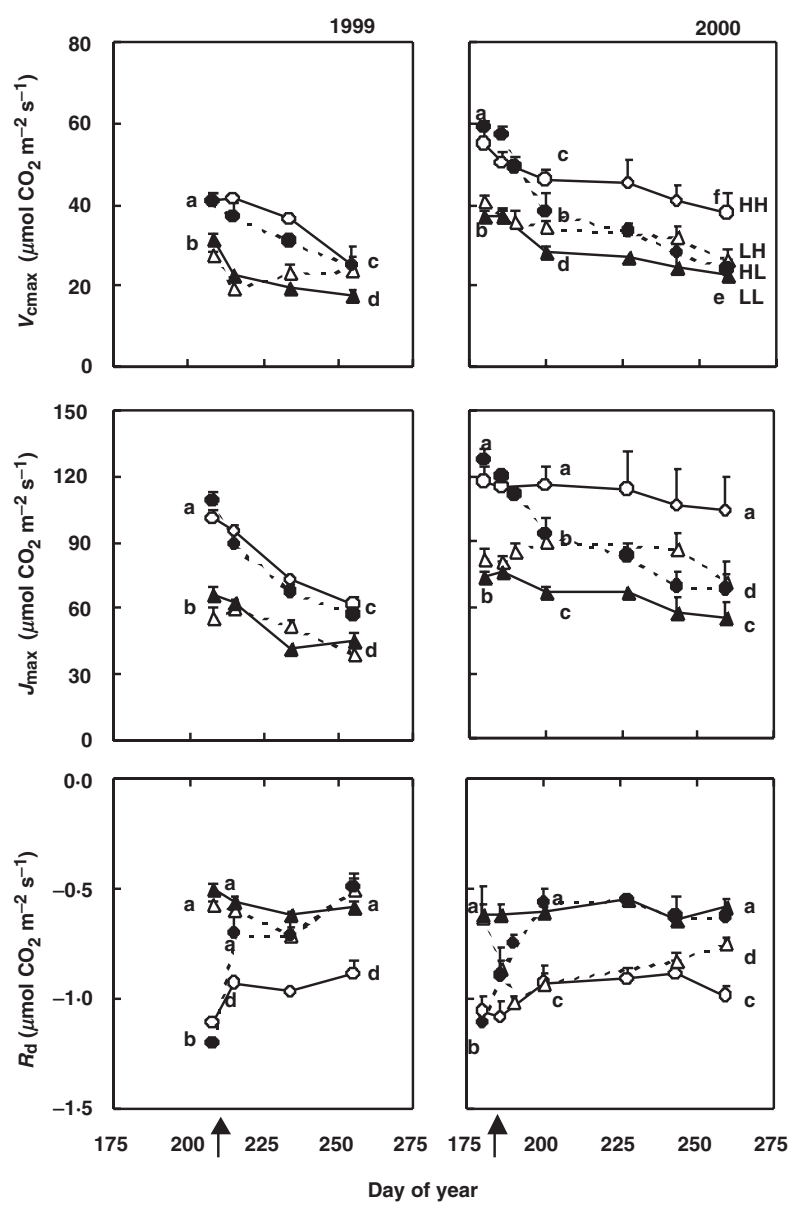

Figure 5. Temporal changes in the maximum carboxylation rate $\left(V_{\text {cmax }}\right)$, the light-saturated electron transport rate $\left(J_{\max }\right)$ and the respiration rate $\left(R_{\mathrm{d}}\right)$ per unit leaf area in 1999 and 2000 . Symbols as in Fig. 3; bars indicate standard errors. The effects of $T, D$ and $I$ were highly significant for all variables $(P<0.001)$ in 1999 and 2000 . Significant differences on a few dates are indicated by letters. 

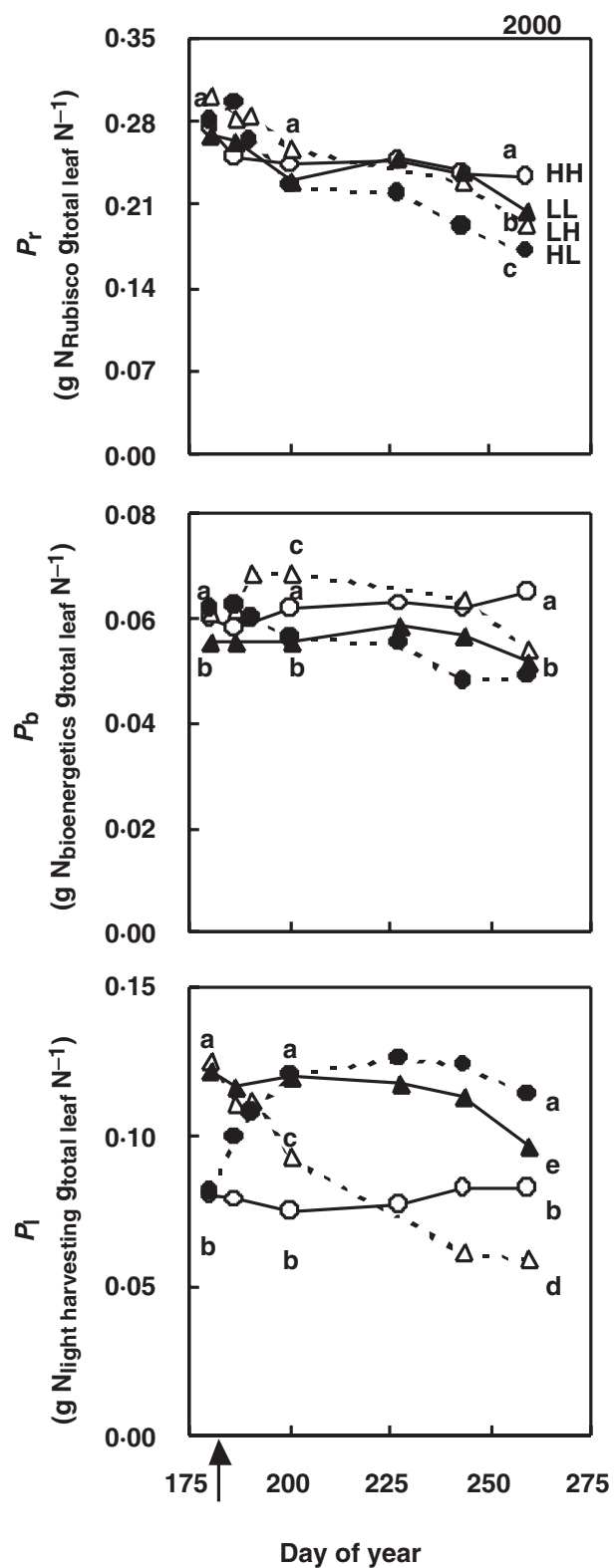

Figure 6. Temporal changes of the nitrogen investments into carboxylation $\left(P_{\mathrm{r}}\right)$, bioenergetics $\left(P_{\mathrm{b}}\right)$ and light harvesting $\left(P_{1}\right)$ in 2000, computed according to Niinemets \& Tenhunen (1997). Symbols as in Fig. 3. $T$ had a smaller effect on $P_{\mathrm{r}}$ than $D(P=0.042$ and $P<0 \cdot 001)$, and $P_{\mathrm{b}}$ was affected more by $T$ than by $D(P<0 \cdot 001$ and $P=0.034)$. $I$ was NS for $P_{\mathrm{r}}$ and $P_{\mathrm{b}} . T, D$ and $I$ had a highly significant effect on $P_{1}(P<0 \cdot 001)$. Significant differences on a few dates are indicated by letters.

\section{Leaf $\mathbf{N}$ partitioning within the photosynthetic apparatus}

In 1999, leaf $\mathrm{N}$ partitioning between carboxylation and bioenergetics did not change significantly after transfer as compared with plants grown in constant LL and HH (not shown). However, in 2000, the fraction of leaf $\mathrm{N}$ invested into carboxylation decreased significantly for HL leaves as compared with HH leaves (Fig. 6). Concurrently, the frac- tion of $\mathrm{N}$ invested into carboxylation did not change between LL and LH treatments. The fraction of leaf $\mathrm{N}$ invested in bioenergetics increased significantly in $\mathrm{LH}$ and decreased in HL trees after transfer as compared with constant LL and HH, respectively. These changes were significant 2 weeks after transfer for LH leaves $(6.9 \%$ versus $5.6 \%)$ and 3 weeks after transfer for HL leaves $(5.6 \%$ versus 6.2\%). In 1999 (not shown) and 2000 (Fig. 6), the fraction of leaf $\mathrm{N}$ invested into light capture decreased significantly in LH and increased in HL treatments after transfer as compared with controls. For HL leaves, the fraction of leaf $\mathrm{N}$ invested into light capture became similar to values for LL leaves ( $12 \%$ instead of $8 \%$ initially) within 2 weeks of transfer. The delay for full acclimation of $P_{1}$ in LH leaves was around 1.5 months.

After LH transfer, the relative changes in $V_{\text {cmax }}$ resulted mainly from an increase in $\mathrm{N}_{\mathrm{a}}$, whereas $P_{\mathrm{r}}$ decreased slightly with time (Fig. 7). However, after HL transfer, the relative changes in $V_{\text {cmax }}$ resulted from changes in $\mathrm{N}_{\mathrm{a}}$ and $P_{\mathrm{r}}$ equally. Concurrently, changes in $\mathrm{N}_{\mathrm{a}}$ and $P_{\mathrm{b}}$ drove the relative changes in $J_{\max }$ after HL transfer equally. After LH transfer, the relative changes in $J_{\max }$ resulted mainly from changes in $P_{\mathrm{b}}$ initially (until $20 \mathrm{~d}$ after transfer), and were then driven mainly by an increase in $\mathrm{N}_{\mathrm{a}}$.

For the LL, HH and HL treatments, the $P_{\mathrm{r}}$ values computed according to Niinemets \& Tenhunen (1997) were well correlated to those computed directly from measured total $\mathrm{N}$ and Rubisco amounts (Fig. 8). However, $P_{\mathrm{r}}$ values estimated from Niinemets \& Tenhunen (1997) were $45 \%$ lower than those computed directly. Furthermore, $P_{\mathrm{r}}$ values of

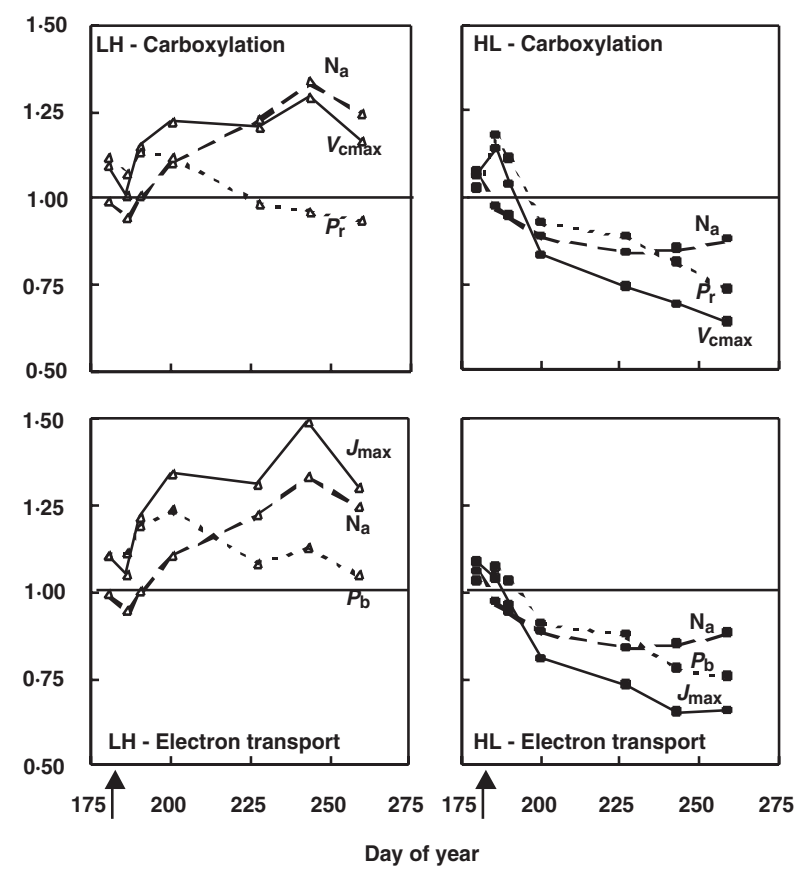

Figure 7. Variations in $V_{\text {cmax }}$ and $J_{\max }$ and in their components $\mathrm{N}_{\mathrm{a}}, P_{\mathrm{r}}$ and $P_{\mathrm{b}}$ as a function of time after $\mathrm{HL}$ or $\mathrm{LH}$ transfer. Values for $\mathrm{HL}$ and $\mathrm{LH}$ leaves are normalized to those observed on control $\mathrm{HH}$ and LL leaves, respectively. 


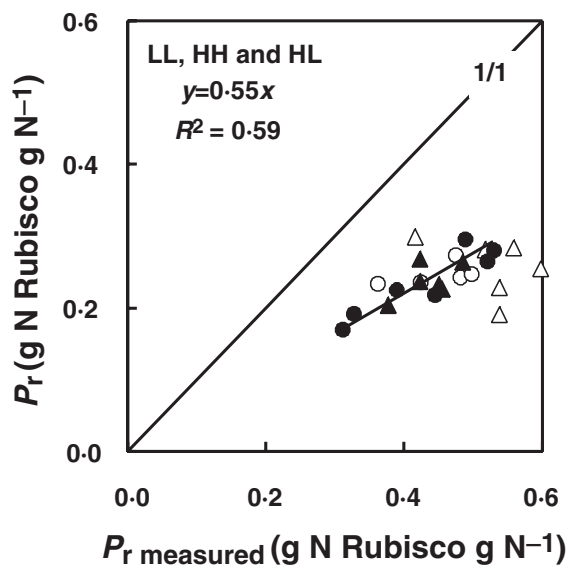

Figure 8. Comparison between the nitrogen investment into carboxylation computed according to Niinemets \& Tenhunen $(1997)\left(P_{\mathrm{r}}\right)$ and that computed directly from measured total nitrogen and Rubisco amounts $\left(P_{\mathrm{r} \text { measured }}\right)$. Symbols as in Fig. 3. The fitted curve and equation given in the graph correspond only to $\mathrm{LL}, \mathrm{HH}$ and $\mathrm{HL}$ treatments

LH leaves computed according to Niinemets \& Tenhunen (1997) decreased from 30 to $19 \%$ after transfer, whereas those computed directly from $\mathrm{N}$ and Rubisco amounts increased from 41 to $59 \%$.

\section{DISCUSSION}

\section{Acclimation ability in fully developed walnut leaves}

In 2000, photosynthetic acclimation occurred in fully developed walnut (Juglans nigra x regia) leaves after a sudden change in light regime, and was demonstrated by the increase in photosynthetic capacity in the LH treatment and the decrease in the HL treatment. Acclimation of photosynthetic capacity in adult leaves was reported to occur in response to sudden changes in light microclimate in Phaseolus vulgaris (von Caemmerer \& Farquhar 1984), Lolium multiflorum (Sebaa, Prioul \& Brangeon 1987), C. sativus (Evans 1989), Abies amabilis (Brooks et al. 1994) and G. $\max$ (Pons \& Pearcy 1994) after high-to-low light transfers, and in adult leaves of Hedera helix (Bauer \& Thoni 1988), Quercus rubra and Acer saccharum (Naidu \& DeLucia 1997) after low-to-high light transfers. In our study, photosynthetic capacity decreased by $35-40 \%$ in HL trees and increased by $25-45 \%$ in $\mathrm{LH}$ trees within $20 \mathrm{~d}$ of transfer, whereas full acclimation of $V_{\text {cmax }}$ and $J_{\max }$ to the new light regime was not observed $50 \mathrm{~d}$ after transfer. The fact that the leaf structure is fixed after the completion of leaf development could explain the lack of full acclimation. This is consistent with the lack of full acclimation of photosynthetic capacity in $Q$. rubra and A. saccharum 1 month after a low-to-high light transfer (Naidu \& DeLucia 1997). In $A$. amabilis, full acclimation was observed only 23 months after shading (Brooks et al. 1994). However, abscission of needles with a less favourable carbon balance, together with the large gradient in needle properties within a single shoot, could lead to an illusion of perfect acclimation. In contrast, photosynthetic capacity acclimated almost fully to the new, low-light regime within $10 \mathrm{~d}$ in P. vulgaris (von Caemmerer \& Farquhar 1984) and L. multiflorum (Sebaa et al. (1987), and within $12 \mathrm{~d}$ in G. $\max$ (Pons \& Pearcy 1994). As anticipated by Pearcy \& Sims (1994), these results suggest that the time required for the completion of photosynthetic acclimation is higher for fully developed leaves of woody (more than 1 month) than herbaceous (less than 2 weeks) species. However, we anticipate that studies on fast-growing trees (e.g. poplar) and slow-growing herbaceous species could lead to a distinction between species exhibiting low versus high photosynthetic activities rather than between woody versus herbaceous species.

In contrast to the dynamics of acclimation observed for $V_{\text {cmax }}$ and $J_{\max }$, the dark respiration rate of fully developed walnut leaves acclimated fully within 1-2 weeks of the HL or LH transfer. Such a short delay in the acclimation of $R_{\mathrm{d}}$ is consistent with results obtained in both woody (Naidu \& DeLucia 1997) and herbaceous (Sims \& Pearcy 1991; Pons \& Pearcy 1994) species after low-to-high or high-to-low transfers. The increase and decrease in leaf dark respiration rate in LH and HL leaves, respectively, were probably due to the costs of carbohydrate processing and transport and/ or protein turnover (Irving \& Silsbury 1988; De Visser, Spitters \& Bouma 1992).

Given that climatic conditions were similar in 1999 and 2000, the comparison of the results obtained in both years shows that the capacity for photosynthetic acclimation depended on leaf age at the time of change in light regime. In walnut, fully developed leaves exhibited a poor capacity for photosynthetic acclimation when the transfer was made $91 \mathrm{~d}$ after bud burst (1999), whereas they were largely able to acclimate when the transfer was made $58 \mathrm{~d}$ after bud burst (2000). Leaf age and/or ontogenic status has been shown to strongly influence photosynthetic acclimation capacity in young versus adult leaves of Fragaria virginiana (Jurik, Chabot \& Chabot 1979), H. helix (Bauer \& Thoni 1988) and Alocasia macrorrhiza (Sims \& Pearcy 1992). In contrast, both 1-year-old and 4-year-old leaves of A. amabilis acclimated after shading (Brooks et al. 1994). These results show that, along with leaf production and turnover, the acclimation capacity of leaves of different ages in response to changes in light regime should be taken into account when analysing the ecological roles of photosynthetic acclimation.

\section{Changes in non-structural carbohydrates and leaf mass : area ratio}

Foliar TNCs vary spatially along light gradients in tree canopies (Kull \& Niinemets 1998; Niinemets \& Kull 1998; Le Roux et al. 1999a). The amount of TNCs in leaves is generally assumed to reflect the carbon (C) balance between acquisition and export (Chapin, Schulze \& Mooney 1990) in source-sink interactions. Changes in light regime during 
2000 induced a modification of TNCs, which suggests that source-sink relationships in LH and HL leaves were modified. However, a decrease in photosynthetic capacity in HL leaves did not reduce starch pool of the leaves, as reported by Thorne \& Koller (1974) for shaded plants of G. max. The high amount of starch found in HL leaves after transfer was presumably because of a decrease in $\mathrm{C}$ demand (respiration rate and protein synthesis), as well as higher chlorophyll content and electron transport capacity as compared with 'true' shade leaves. In contrast to G. max (Thorne \& Koller 1974), the amount of GFS in HL leaves of walnut decreased through the experiment and was independent of starch content. In both the HL and the LH treatments, changes in GFS were concurrent with changes in $\mathrm{N}_{\mathrm{a}}$, suggesting a strong interaction between these two pools. Although $\mathrm{C}$ demand for respiration and protein synthesis increased during photosynthetic acclimation in LH leaves, limitation of C exportation could be responsible for starch accumulation, as reported by Silvius, Chatterton \& Kremer (1979) for fully developed leaves of G. max transferred to bright light.

In many species, LMA varies according to the light environment and largely drives the differences observed for some leaf photosynthetic characteristics (e.g. $\mathrm{N}_{\mathrm{a}}$ ) within the tree canopy (Niinemets 1997; Niinemets \& Kull 1998; Le Roux et al. 1999a; Rosati, Day \& DeJong 2000). The TNCfree LMA quantifies the allocation of $\mathrm{C}$ to the leaf structures. Allocation of biomass to the leaf structures was higher in $\mathrm{HH}$ and HL than in LL and $\mathrm{LH}$ treatments, respectively. After transfer, TNC-free LMA in the HL treatment did not change as compared with values observed for the constant light-grown plants. This shows that physiological and biochemical, rather than structural, modifications controlled photosynthetic acclimation. However, in LH leaves, an increase in LMA occurred during photosynthetic acclimation. This increase was independent of the accumulation of TNC and protein, and could be due to a larger production of secondary metabolites like phenolics or flavonoids (Christian Jay-Allemand, personal communication).

\section{Importance of concurrent changes in total leaf $\mathbf{N}$ and $\mathbf{N}$ partitioning between photosynthetic functions for photosynthetic acclimation}

Generally, photosynthetic capacities per unit leaf area are tightly correlated to the amount of leaf $\mathrm{N}$ invested into the different photosynthetic functions (Evans \& Seemann 1989). Thus, photosynthetic light acclimation in fully developed leaves following a change in light regime can be driven either by changes in $\mathrm{N}_{\mathrm{a}}$ and/or by partitioning of total leaf $\mathrm{N}$ between the different pools of the photosynthetic machinery, as expressed by $P_{\mathrm{r}}$ and $P_{\mathrm{b}}$. In our study, the relative changes in $V_{\text {cmax }}$ or $J_{\max }$ resulted equally from changes in $\mathrm{N}_{\mathrm{a}}$ and $P_{\mathrm{r}}$ or $P_{\mathrm{b}}$ after a HL transfer. The qualitative agreement observed for the HL treatment between the $P_{\mathrm{r}}$ values computed according to Niinemets \& Tenhunen (1997) and those computed directly from the measured amounts of total $\mathrm{N}$ and Rubisco provided some confidence in the observed behaviour of $P_{\mathrm{r}}$. Only a few studies have actually surveyed the changes in photosynthetic capacity, $\mathrm{N}_{\mathrm{a}}$ and leaf $\mathrm{N}$ partitioning after a change in light regime. In G. max, the decrease in $V_{\text {cmax }}$ resulted from a decrease in both $\mathrm{N}_{\mathrm{a}}$ and $P_{\mathrm{r}}$ after shading (Pons \& Pearcy 1994). Concurrently, the decrease in $J_{\max }$ resulted mainly from changes in $\mathrm{N}_{\mathrm{a}}$, whereas $P_{\mathrm{b}}$ remained constant. In $A$. amabilis, Brooks et al. (1994) showed that acclimation of photosynthetic capacity resulted only marginally from changes in $\mathrm{N}_{\mathrm{a}}$ after a high-to-low light transfer. Therefore, changes in both $\mathrm{N}_{\mathrm{a}}$ and leaf $\mathrm{N}$ partitioning between the different photosynthetic functions can control photosynthetic acclimation to shading in fully developed leaves.

After the LH transfer, changes in $V_{\text {cmax }}$ resulted mainly from an increase in $\mathrm{N}_{\mathrm{a}}$, whereas $P_{\mathrm{r}}$ computed according to Niinemets \& Tenhunen (1997) decreased with time. An increase in $\mathrm{N}_{\mathrm{a}}$ after a low-to-high light transfer was observed in Q. rubra and A. saccharum (Naidu \& DeLucia 1997). Similarly, an increase in soluble proteins was observed in H. helix after an increase in light level (Bauer \& Thoni 1988). However, to our knowledge, changes in the partitioning of leaf $\mathrm{N}$ have not been quantified accurately after a transfer of mature shade leaves to bright light. The discrepancy observed for the LH treatment between the $P_{\mathrm{r}}$ values computed according to Niinemets \& Tenhunen (1997) (i.e. from the $V_{\text {cmax }}$ values estimated on the basis of the $\mathrm{CO}_{2}$ partial pressure in the substomatal spaces) and those computed directly from measured total $\mathrm{N}$ and Rubisco amounts suggests that (i) the investment of leaf $\mathrm{N}$ into carboxylation actually increased, and (ii) an enhanced limitation of photosynthesis by $\mathrm{CO}_{2}$ diffusion into the leaves occurred when the photosynthetic capacity of $\mathrm{LH}$ leaves increased. Several studies demonstrated that a significant diffusive resistance to $\mathrm{CO}_{2}$ exists between the intercellular spaces and carboxylation sites, which leads to underestimation of maximal carboxylation rate (Lloyd et al. 1992; Loreto et al. 1992; Epron et al. 1995). In our study, the internal conductance $\left(g_{\mathrm{i}}\right)$ to $\mathrm{CO}_{2}$ transfer measured before transfer was much lower in shade (around $100 \mathrm{mmol} \mathrm{m}^{-2} \mathrm{~s}^{-1}$ ) than in sun (around $250 \mathrm{mmol} \mathrm{m}^{-2} \mathrm{~s}^{-1}$ ) leaves (C. Piel et al., unpublished results). Using these $g_{\mathrm{i}}$ values to calculate $V_{\text {cmax }}$ led to a $35-45 \%$ increase in both computed $V_{\text {cmax }}$ and $\mathrm{N}$ investment into carboxylation, calculated from Eqn 1. This underlines the importance of internal conductance for the computation of $V_{\text {cmax }}$ and $\mathrm{N}$ investment, as suggested by Niinemets \& Tenhunen (1997).

The strong increase in the fraction of leaf $\mathrm{N}$ invested into light harvesting after a HL transfer is consistent with results reported by Evans (1989) in C. sativus, by Pons \& Pearcy (1994) in G. max and by Brooks et al. (1994) in A. amabilis. In our study and that of Pons \& Pearcy (1994), $P_{1}$ acclimated fully within $<2$ weeks of transfer. Such an increase in $P_{1}$ enhances the capture of the major limiting resource for shade leaves, i.e. light (Evans 1987; Evans \& Seemann 1989). In contrast, the decrease of $P_{1}$ in LH leaves was less rapid, and $P_{1}$ values only acclimated fully $50 \mathrm{~d}$ after transfer. $P_{1}$ decreased only weakly in leaves of $Q$. rubra and $A$. saccharum transferred to bright light (Naidu \& DeLucia 1998). 


\section{CONCLUSIONS}

In this study, we demonstrated that concurrent changes in total leaf $\mathrm{N}$ and $\mathrm{N}$ investment in carboxylation, electron transport and light harvesting drove photosynthetic acclimation in mature leaves of hybrid walnut. The relative roles of the different changes differed between HL and LH transfers and depended on the time after transfer. Our results suggest that a strong limitation of photosynthesis by $\mathrm{CO}_{2}$ diffusion occurred after a transfer to high light. The contrast between the data obtained in 1999 and in 2000 underlined the effect of leaf age on photosynthetic acclimation ability.

\section{ACKNOWLEDGMENTS}

This work was a funded part of the twinning agreement between the Institut National de Recherche Agronomique (INRA) and the Macaulay Land Use Research Institute (MLURI). E.F., X.L.R., P.M and R.W. acknowledge financial support from the Alliance programme 99-120. The $\mathrm{PhD}$ grant to E.F. was funded by INRA and the Auvergne region. The help of Jacqueline Liebert (Plant ecology Unit, CNRS/University Paris II) for chlorophyll analyses, of Adrian Walcroft (Lancare Research, Massey University, Palmerston North) for SAS fitting procedure and of Mike Proe (MLURI Aberdeen) for manuscript reviewing is acknowledged gratefully.

\section{REFERENCES}

Anten N.P.R., Hernandez R. \& Medina E.M. (1996) The photosynthetic capacity and leaf nitrogen concentration as related to light regime in shade leaves of a montane tropical forest tree, Tetrorchidium rubrivenium. Functional Ecology 10, 491-500.

Anten N.P.R. \& Werger M.J.A. (1996) Canopy structure and nitrogen distribution in dominant and subordinate plants in a dense stand of Amaranthus dubius L with a size hierarchy of individuals. Oecologia 105, 30-37.

Bauer H. \& Thoni W. (1988) Photosynthetic light acclimation in fully developed leaves of the juvenile and adult life phases of Hedera helix. Physiologia Plantarum 73, 31-37.

Besford R.T. (1986) Changes in some Calvin cycle enzymes of the tomato during acclimation to irradiance. Journal of Experimental Botany 37, 200-210.

Boardman N.K. (1977) Comparative photosynthesis of sun and shade plants. Annual Review of Plant Physiology 28, 355-377.

Boehringer S.A. (1984) Methods of Enzymatic Food Analysis Using Single Reagents. Boehringer Mannheim GmbH (DEU), Mannheim, Germany.

Brooks J.R., Hinckley T.M. \& Sprugel D.G. (1994) Acclimation responses of mature Abies amabilis sun foliage to shading. Oecologia 100, 316-324.

Burkey K.O. \& Wells R. (1991) Response of soybean photosynthesis and chloroplast membrane - function to canopy development and mutual shading. Plant Physiology 97, 245-252.

von Caemmerer S. \& Farquhar G.D. (1984) Effects of partial defoliation, changes of irradiance during growth, short-term water-stress and growth at enhanced $\mathrm{P}\left(\mathrm{CO}_{2}\right)$ on the photosyn- thetic capacity of leaves of Phaseolus vulgaris L. Planta 160,320329.

Catt J.W. \& Millard P. (1988) The measurement of Ribulose 1,5bisphosphate carboxylase/oxygenase concentration in the leaves of potato plants by enzyme linked immunosorbtion assays. Journal of Experimental Botany 39, 157-164.

Chapin F.S. III, Schulze E.D. \& Mooney H.A. (1990) The ecology and economics of storage in plants. Annual Review of Ecology and Systematics 21, 423-447.

Chazdon R.L. \& Kaufmann S. (1993) Plasticity of leaf anatomy of two rain forest shrubs in relation to photosynthetic light acclimation. Functional Ecology 7, 385-394.

Chow W.S., Qian L., Goodchild D.J. \& Anderson J.M. (1988) Photosynthetic acclimation of Alocasia macrorrhiza (L.) G. Don to growth irradiance: structure, function and composition of chloroplasts. Australian Journal of Plant Physiology 15, 107-122.

Davies E.C., Chow W.S., le Fay J.M. \& Jordan B.R. (1986) Acclimation of tomato leaves to changes in light intensity: effects on the function of the thylakoid membrane. Journal of Experimental Botany 37, 211-220.

De la Torre W.R. \& Burkey K.O. (1990) Acclimation of barley to changes in light intensity - chlorophyll organization. Photosynthesis Research 24, 117-125.

De Visser R., Spitters C.J.T. \& Bouma T.J. (1992) Energy cost of protein turnover: theoretical calculation and experimental estimation from regression of respiration on protein concentration of full-grown leaves. In Molecular, Biochemical and Physiological Aspects of Plant Respiration (eds H. Lambers \& L. H. W. van der Plas), pp. 493-508. SPB Academic Publishing, The Hague, The Netherlands.

DeJong T.M. \& Doyle J.F. (1985) Seasonal relationships between leaf nitrogen content (photosynthetic capacity) and leaf canopy light exposure in peach (Prunus persica). Plant, Cell and Environment 8, 701-706.

Epron D., Godard D., Cornic G. \& Genty B. (1995) Limitation of net $\mathrm{CO}_{2}$ assimilation rate by internal resistances to $\mathrm{CO}_{2}$ transfer in the leaves of two tree species (Fagus sylvatica L. and Castanea sativa Mill.). Plant, Cell and Environment 18, 297-302.

Evans J.R. (1987) The relationship between electron transport components and photosynthetic capacity in pea leaves grown at different irradiances. Australian Journal of Plant Physiology 14, 157-170.

Evans J.R. (1989) Partitioning of nitrogen between and within leaves grown under different irradiances. Australian Journal of Plant Physiology 16, 533-548.

Evans J.R. (1993) Photosynthetic acclimation and nitrogen partitioning within a lucerne canopy: II. Stability through time and comparison with a theoretical optimum. Australian Journal of Plant Physiology 20, 69-82.

Evans J.R. \& Seemann J.R. (1989) The allocation of protein nitrogen in the photosynthetic apparatus: costs, consequences and control. In Photosynthesis (ed. W. R. Briggs), pp. 183-205. Liss A.R., Inc., New York.

Farquhar G.D. \& von Caemmerer S. (1982) Modelling of photosynthetic response to environmental conditions. In Encyclopedia of Plant Physiology, New Series, Vol. 12B: Physiological Plant Ecology II (eds O. L. Lange, P. S. Nobel, C. B. Osmond \& H. Ziegler), pp. 549-587. Springer-Verlag, Berlin.

Field C. \& Mooney H. (1986) The photosynthesis-nitrogen relationship in wild plants. In On the Economy of Form and Function (ed. T. J. Givnish), pp. 25-55. Cambridge University Press, Cambridge.

Gabriel K.R. (1962) Ante-dependence analysis of an ordered set of variables. Annals of Mathematical Statistics 33, 201-212.

Givnish T.J. (1988) Adaptation to sun and shade: a whole-plant perspective. Australian Journal of Plant Physiology 15, 63-92. 
Harley P.C., Thomas R.B., Reynolds J.F. \& Strain B.R. (1992) Modelling photosynthesis of cotton grown in elevated $\mathrm{CO}_{2}$. Plant, Cell and Environment 15, 271-282.

Hikosaka K. (1996) Effects of leaf age, nitrogen nutrition and photon flux density on the organization of the photosynthetic apparatus in leaves of a vine (Ipomoea tricolor Cav) grown horizontally to avoid mutual shading of leaves. Planta 198, 144-150.

Hikosaka K. \& Terashima I. (1995) A model of the acclimation of photosynthesis in the leaves of $\mathrm{C}_{3}$ plants to sun and shade with respect to nitrogen use. Plant, Cell and Environment 18, 605618.

Hirose T.\& Werger M.J.A. (1987) Maximizing daily canopy photosynthesis with respect to the leaf nitrogen allocation pattern in the canopy. Oecologia 72, 520-526.

Irving D.E. \& Silsbury J.H. (1988) The respiration of mature field bean (Vicia faba L.) leaves during prolongated darkness. Annals of Botany 62, 473-479.

Jurik T.W., Chabot J.F. \& Chabot B.F. (1979) Ontogeny of photosynthetic performance in Fragaria virginiana under changing light regimes. Plant Physiology 63, 542-547.

Kappel F. \& Flore J.A. (1983) Effect of shade on photosynthesis, specific leaf weight, leaf chlorophyll content and morphology of young peach trees. Journal of the American Society for Horticultural Science 108, 541-544.

Kull O. \& Niinemets U. (1998) Distribution of leaf photosynthetic properties in tree canopies: comparison of species with different shade tolerance. Functional Ecology 12, 472-479.

Le Roux X., Sinoquet H. \& Vandame M. (1999a) Spatial distribution of leaf dry weight per area and leaf nitrogen concentration in relation to local radiation regime within an isolated tree crown. Tree Physiology 19, 181-188.

Le Roux X., Grand S., Dreyer E. \& Daudet F.A. (1999b) Parameterization and testing of a biochemically based photosynthesis model for walnut (Juglans regia) trees and seedlings. Tree Physiology 19, 481-492.

Le Roux X., Walcroft A.S., Daudet F.A., Sinoquet H., Chaves M.M., Rodrigues A. \& Osorio L. (2001) Photosynthetic light acclimation in peach leaves: importance of changes in mass : area ratio, nitrogen concentration and leaf nitrogen partitioning. Tree Physiology 21, 377-386.

Lloyd J., Syvertsen J.P., Kriedemann P.E. \& Farquhar G.D. (1992) Low conductances for $\mathrm{CO}_{2}$ diffusion from stomata to the sites of carboxylation in leaves of woody species. Plant, Cell and Environment 15, 873-899.

Loreto F., Harley P.C., Di Marco G. \& Sharkey T.D. (1992) Estimation of mesophyll conductance to $\mathrm{CO}_{2}$ flux by three different methods. Plant Physiology 98, 1437-1443.

Naidu S.L. \& DeLucia E.H. (1997) Acclimation of shade-developed leaves on saplings exposed to late-season canopy gaps. Tree Physiology 17, 367-376.

Naidu S.L. \& DeLucia E.H. (1998) Physiological and morphological acclimation of shade-grown tree seedlings to late-season canopy gap formation. Plant Ecology 138, 27-40.

Niinemets Ü. (1997) Distribution patterns of foliar carbon and nitrogen as affected by tree dimensions and relative light conditions in the canopy of Picea abies. Trees-Structure and Function 11, 144-154.

Niinemets Ü. \& Kull O. (1998) Stoichiometry of foliar carbon constituents varies along light gradients in temperate woody canopies: implication for foliage morphological plasticity. Tree Physiology 18, 467-479.

Niinemets Ü., Kull O. \& Tenhunen J.D. (1998) An analysis of light effects on foliar morphology, physiology and light interception in temperate deciduous woody species of contrasting shade tolerance. Tree Physiology 18, 681-696.

Niinemets Ü. \& Tenhunen J.D. (1997) A model separating leaf structural and physiological effects on carbon gain along light gradients for the shade-tolerant species Acer saccharum. Plant, Cell and Environment 20, 845-866.

Pearcy R.W. \& Sims D.A. (1994) Photosynthetic acclimation to a changing light environment: scaling from the leaf to the whole plant. In Exploitation of Environmental Heterogeneity by Plants (ed. M. M. Caldwell), pp. 145-174. Academic Press, San Diego, CA.

Pons T.L. \& Pearcy R.W. (1994) Nitrogen reallocation and photosynthetic acclimation in response to partial shading in soybean plants. Physiologia Plantarum 92, 636-644.

Porra R.J., Thompson W.A. \& Kriedemann P.E. (1989) Determination of accurate extinction coefficients and simultaneous equations for assaying chlorophylls $a$ and $b$ extracted with four different solvents: verification of the concentration of chlorophyll standards by atomic absorption spectroscopy. Biochimica et Biophysica Acta 975, 384-394.

Prioul J.-L., Brangeon J. \& Reyss A. (1980) Interaction between external and internal conditions in the development of photosynthetic features in a grass leaf. Plant Physiology 66, 770-774.

Rôças G., Barros C.F. \& Scarano F.R. (1997) Leaf anatomy of Alchornea triplinervia (Euphorbiaceae) under distinct light regimes in a Brazilian montane Atlantic rain forest. Trees 11, 469-473.

Rosati A., Day K.R. \& DeJong T.M. (2000) Distribution of leaf mass per unit area and leaf nitrogen concentration determine partitioning of leaf nitrogen within tree canopies. Tree Physiology 20, 271-276.

Sebaa E.D., Prioul J.L. \& Brangeon J. (1987) Acclimation of adult Lolium multiflorum leaves to changes in irradiance: effect on leaf photosynthesis and chloroplast ultrastructure. Journal of Plant Physiology 127, 431-441.

Seemann J.R. (1989) Light adaptation/acclimation of photosynthesis and the regulation of ribulose-1,5-bisphosphate carboxylase activity in sun and shade plants. Plant Physiology 91, 379386.

Seemann J.R., Sharkey T.M., Wang J. \& Osmond C.B. (1987) Environmental effects on photosynthesis, nitrogen-use efficiency and metabolite pools in leaves of sun and shade plants. Plant Physiology 84, 796-802.

Silvius J.E., Chatterton N.J. \& Kremer D.F. (1979) Photosynthate partitioning in soybean leaves at two irradiance levels. Comparative response of acclimated and unacclimated leaves. Plant Physiology 64, 872-875.

Sims D.A. \& Pearcy R.W. (1989) Photosynthetic characteristics of a tropical forest understorey herb, Alocasia macrorrhiza, and a related crop species, Colocasia esculenta grown in contrasting light environments. Oecologia 79, 53-59.

Sims D.A. \& Pearcy R.W. (1991) Photosynthesis and respiration in Alocasia macrorrhiza following transfers to high and low light. Oecologia 86, 447-453.

Sims D.A. \& Pearcy R.W. (1992) Response of leaf anatomy and photosynthetic capacity in Alocasia macrorrhiza (Araceae) to a transfer from low to high light. American Journal of Botany 79, 449-455.

Thorne J.H. \& Koller H.R. (1974) Influence of assimilate demand on photosynthesis, diffusive resistances, translocation and carbohydrate levels of soybean leaves. Plant Physiology 54, 201-207.

Turnbull M.H., Doley D. \& Yates D.J. (1993) The dynamics of photosynthetic acclimation to changes in light quantity and quality in three Australian rain-forest tree species. Oecologia 94, 218-228.

Received 20 April 2001; received in revised form 6 August 2001; accepted for publication 6 August 2001 